\title{
Emotion Regulation, Stress, and Well-Being in Academic Education: Analyzing the Effect of Mindfulness-Based Intervention
}

\author{
Liana Santos Alves Peixoto ${ }^{1}\left[{ }^{(1)}\right.$. Sonia Maria Guedes Gondim² ${ }^{2}$. \\ Cícero Roberto Pereira ${ }^{3}$ (i)
}

Accepted: 8 July 2021 /Published online: 23 August 2021

(c) Associação Brasileira de Psicologia 2021

\begin{abstract}
Recent studies point to an increase in psychological distress among graduate students. The aim of this study was to analyze the effects of mindfulness practices on emotion regulation, on the perception of stress, and on the psychological well-being of graduate students. Forty-five (45) graduate students participated in the study, divided into an intervention and a control group. Questionnaires were applied for self-assessment of mindfulness, perceived stress, and psychological well-being, in addition to qualitative interviews in the pre- and post-timeframes of a mindfulnessbased intervention. Quantitative data were analyzed using ANOVAs for repeated measures, while the interviews were analyzed using the thematic content analysis technique. The results indicated increases in the levels of mindfulness and psychological well-being, and a reduction in perceived stress in the intervention group, post-intervention. The interviews indicated the presence of ambivalent emotions in relation to graduate studies and the development of new strategies to cope with the stress in this work context. The main contribution of the study was to present empirical evidence of the effectiveness of mindfulness practices in the graduate-level education context, allowing students to become more capable of dealing with the challenges of an academic career.
\end{abstract}

Keywords Mindfulness · Emotion regulation · Psychological well-being · Perceived stress $\cdot$ Academic education

Liana Santos Alves Peixoto

liana.sap@gmail.com

1 Institute of Psychology, Federal University of Bahia, Emotions, Feelings and Affections in Work

Contexts (EMOTRAB), Estrada de Sao Lázaro, Sao Lázaro, Salvador, BA, Brasil

2 Institute of Psychology, Federal University of Bahia, Estrada de São Lázaro, São Lázaro, Salvador, BA, Brasil

3 Institute of Psychology, Federal University of Paraiba, Centro de Ciências Humanas Letras E Artes - Campus I, AC Cidade Universitária João Pessoa,, Castelo Branco, CEP: 58051970 João Pessoa, PB, Brasil 
In recent decades, there has been an increase in studies on the constructs that are related to subjective (Diener, 1984; Diener et al., 2018; Jovanović, 2015) and psychological (Disabato et al., 2016; Ryff, 1989) individual well-being (Sonnentag, 2015), especially in those contexts with a strong presence of stressors such as academic education (Klainin-Yobas et al., 2016; Schmidt \& Hansson, 2018; Smith \& Yang, 2017). According to Faro (2013a), graduate school is a complex reality that requires various adjustments, from career planning to facing daily challenges in the exercise of this work activity, and recent studies point to an increase in psychological distress among graduate students (Farrer et al., 2016; Marais et al., 2018; Mendes \& Iora, 2014). The relationship of the students with their advisors, the few resources available, the work overload, the arduous learning of scientific writing, and the preparation and development of the research project proves to be contributing factors to this distress (Faro, 2013a; Galvan et al., 2015; Santos et al., 2015). Thus, it becomes relevant to identify and deepen our understanding of the predictors of health and well-being in this population, to guide actions in the area of academic education.

It is observed in the scientific literature (Gross \& John, 2003; Santana \& Gondim, 2016) that well-being is associated with emotion regulation, defined as a psychological process that can occur both at the conscious level and automatically. It aims to modulate the way emotions are felt and expressed for the purpose of adaptation and social adjustment (Gross, 2015). Mindfulness has been considered an ally in the process of emotion regulation. Recent studies have demonstrated positive effects of mindfulness on the individual's health, decreasing the intensity of distress, accelerating emotional recovery, and increasing the ability to engage in goal-oriented behavior (Bullis et al., 2014; MacDonald \& Baxter, 2017; Mahmoudzadeh et al., 2015; Mandal et al., 2017; Roemer et al., 2015; Shapiro et al., 2006). In mindfulness training, individuals learn to self-regulate their attention (sustaining it or changing the focus, when necessary). They also learn to observe mental and emotional patterns, maintaining an attitude of openness and acceptance, without ignoring unpleasant experiences (Bishop et al., 2004; Iani et al., 2019; Kabat-Zinn, 2017; Shapiro et al., 2006). Acceptance-based strategies for responding to negative emotions were associated with less psychological symptoms and more well-being (Baer et al., 2006). This acceptance is not to be confused with passivity in the face of reality. More recent empirical evidence (Ford et al., 2018) indicates that there is no association between mental acceptance of the negative emotional experience and passive acceptance of the negative situation. Thus, it is suggested that there is an association between the practice of mindfulness and processes of emotion regulation in the promotion of greater general well-being (Brown \& Ryan, 2003; Mitmansgruber et al., 2009).

According to Baer et al. (2006), mindfulness would involve cognitive, attitudinal, and affective aspects, when contemplating and cultivating thoughts, feelings, and physical sensations without trying to avoid them and not becoming overly engaged in them. It is based on an attitude of non-judgment, being anchored in the present moment, and avoiding automatic and reactive forms (Bishop et al., 2004; Iani et al., 2019). According to Kabat-Zinn (2017), mindfulness as a life practice is associated with the introjection of seven attitudes that can help change the individual's 
perspective and relationship with him/herself, with others, and with everyday situations: non-judging, patience, beginner's mind, confidence, non-striving, acceptance, and letting go. In being conceived as a posture towards life, a set of attitudes, and a state of consciousness to be reached, mindfulness makes use of formal and informal practices for personal development (Crane et al., 2014; Goldberg et al., 2014; Parsons et al., 2017).

The attention, intention, and attitudes cultivated with the practice of mindfulness, for Shapiro et al. (2006), help in the process of emotion regulation because it promotes a change in perspective in the interpretation of reality, helps in the consolidation of values, increases emotional and cognitive flexibility, and favors openness to experience. Investigations on the neurobiological aspects involved in the practice of mindfulness have demonstrated changes in the brain regions and neural mechanisms involved in emotional processing (amygdala and prefrontal cortex) with improvements in self-regulation (Doll et al., 2016; Kral et al., 2018; Xiao et al., 2019; Zhang et al., 2019). However, there is demand for further research on how mindfulness would promote an improvement in adaptive functioning, in the choice of regulatory strategies, and in personal well-being (Alkoby et al., 2018; Erisman \& Roemer, 2010), especially in more challenging contexts such as those involving an academic career (Beck et al., 2017; Galante et al., 2017; Regehr et al., 2013).

Some professional careers are more challenging and require more efforts in the use of emotion regulation strategies to maintain or improve individual well-being. Scientific activity is currently going through difficult times due to budget constraints. The situation worsened with the coronavirus pandemic that struck in February 2020. The isolation measures had a clear impact on economic and social life, especially in universities. Additionally, academic life generates a source of stress due to competitiveness and pressure for scientific productivity, causing an emotional overload (Graham et al., 2016; Simonelli-Muñoz et al., 2018).

Given the challenging context for graduate-level education and its impacts on emotion regulation processes, this research sought to contribute to the understanding of the relationship between mindfulness, perception of stress, and psychological well-being. An intervention study was carried out with graduate students with the objective of evaluating the effects of mindfulness practices (mindfulness as a technique) on the increase of psychological well-being (PWB), on decreasing perceived stress, and on increasing full attention (mindfulness treated as a state of consciousness) in a sample of graduate students. The decrease in the level of stress, the increase in PWB, also accompanied by the increase in full attention would be indications that the practice of mindfulness has repercussions on the process of emotion regulation of the study participants. According to Gondim and Rentería-Perez (2019), the scientific value of intervention-based knowledge production is revealed in the capacity of this research design to approach the dynamism of the phenomenon, as is the case in the learning and practice of mindfulness as a resource for emotion regulation purposes, and additionally to evaluate its practical effects. It is expected that the results of this study can be incorporated into the processes for training researchers, making them more capable of ensuring their well-being and dealing with the challenges of a career with continuous and growing demands for emotion regulation. 


\section{Method}

\section{Participants}

Participants were recruited with an invitation letter from the office of the dean of graduate studies and from the graduate student association at the university where the study was conducted. Inclusion criteria comprised the following: (i) be a graduate student and (ii) be enrolled in their studies from the first semester to 6 months before the probable date of their conclusion. Initially, 125 students signed up to participate. Upon applying the inclusion criteria and confirming the interest and availability to participate in the study, 45 students enrolled in graduate studies programs (master's, doctorate, or specialization) were selected.

Most of the participants were women (72\%), aged between 24 and $58(\mathrm{M}=33$; $\mathrm{SD}=8.4)$. Roughly half of them were studying for a Master's degree, $46 \%$ were working on a $\mathrm{PhD}$, and $2 \%$ a Specialist degree. Most of the students (70\%) were receiving a fellowship grant, and 35\% were engaged in other work beyond their graduate studies.

\section{Randomization}

We used a randomized experimental research design to ensure that the only difference between the treatment and control groups was the manipulated variable. For this reason, participants were randomly allocated to one of five groups resulting in 10 to 13 participants per group. Four of these groups received the intervention, and one was the control group. Thus, 37 participants were allocated to the intervention conditions, divided into four subgroups (ranging from eight to 10 participants each). This number of participants per group allowed better monitoring of practices by the instructor. Of these, only one dropped out of the study. The control group included 13 individuals, but only eight remained until the end of the experiment. Data from participants who dropped out of the study were excluded from the analyses. Finally, we conducted a sensitivity power analysis using Webpower (Zhang \& Yuan, 2018), which indicated that our sample size had an $80 \%$ chance of detecting a main effect or interaction effect as small as $f=0.42$ with $\alpha=0.05$.

\section{Mindfulness-Based Intervention}

The intervention was based on the MTi protocol (Mindfulness Trainings International), for which the first author is certified. It was held in eight weekly 2-h meetings in the same room of a federal institution of higher education. Each meeting had a specific theme and was divided into two parts. The first was dedicated to sharing the experiences of homework, reviewing concepts and practices from the previous meeting, and guidance/suggestions for the challenges identified by the participants. 
In the second part, new practices and techniques were introduced to assist in the development of mindfulness, with specific instructions for homework.

The intervention provided for the use of formal and informal practices and proposals for changing habits. The formal ones had a specific structure and duration, with audio support and the need to set aside time and space to carry them out, and were intended to improve the quality of mindfulness. Four formal practices were taught: developing mindfulness while seated; lying down; walking; and moving the body. Informal practices referred to the inclusion of mindfulness in the routine activities of individuals, such as, eating with mindfulness, establishing conversations attentive to body signals, such as breathing, relaxation, or tensing of muscles, among others. The proposals for habit change were intended to stimulate the experience of the seven mindfulness attitudes, such as brushing with the non-dominant hand, which, in general, puts the individual in a beginner's mindset.

In order to offer a variety of stimuli for the development of mindfulness and the seven mindfulness attitudes, which are fundamental to the practice, each week, different formal and informal practices and proposals for habit changes were presented. The homework included a formal practice and at least one informal practice and one habit change.

In general, in the first four meetings, the focus was on understanding what mindfulness is, especially on mindfulness attitudes, and practices centered on the individuals themselves, developing their mindfulness and focusing on their emotions. From the fifth meeting on, the practices also included relationships with other people. In addition to these meetings, there was one extra meeting (for immersion purposes) lasting $3 \mathrm{~h}$ in a space with nature and in silence, to deepen the formal practices taught during the weekly meetings. This meeting also took place on the premises of the same educational institution.

\section{Data Collection Instruments}

Mindfulness Scale (Five Facet Mindfulness Questionnaire - FFMQ-BR): instrument by Baer et al. (2006) validated in the Brazilian context by Barros et al. (2014). The FFMQ presents 39 items related to everyday situations and assesses the individual's general level of mindfulness. Some examples of this instrument's items are "I pay attention to sounds, such as the clock ticking, birds singing, or cars passing by"; "I'm good at finding words that describe my feelings"; "I find it difficult to stay focused on what is happening in the present moment"; "I make judgments about whether my thoughts are good or bad"; "I perceive my feelings and emotions without having to react to them." The overall reliability index (Cronbach's alpha) of the scale was considered satisfactory both before and after the intervention ( 0.88 and 0.87 , respectively).

Perceived Stress Scale (PSS): the original scale by Cohen et al. (1983) was validated for the Brazilian context by Luft et al. (2007). It assesses the degree to which respondents perceive their lives as unpredictable, uncontrollable, and overburdened. It consists of 14 items (e.g., "Have you been feeling that problems accumulate to the point where you believe you cannot overcome them?"; "Have you been feeling that you are dealing well with the important changes that are occurring in your life?") with a Likert scale of responses ranging from zero to four $(0=$ never; $1=$ almost never; $2=$ sometimes; 
$3=$ almost always; $4=$ always). Cronbach's alpha was considered satisfactory both in the pre-intervention (0.87) and post-intervention (0.89) measurements.

Psychological Well-being Scale (PWBS): the original scale (Ryff \& Essex, 1992) was validated for the Brazilian context with a sample of university students by Machado et al. (2013) and used a Likert scale ranging from 1 (completely disagree) to 6 (completely agree). Two dimensions more sensitive to the influence of the development of mindfulness were selected (positive relationship with others and self-acceptance) and some examples of items are "People would describe me as someone willing to share my time with others"; "In general I feel confident and positive about myself."

Cogni (https://cogniapp.com/): Application installed on smartphones that allows the recording of momentary affective states and associated events. The version used allows viewing the data in the form of a report for each participant about their mood, momentary emotions, and contextualization of emotions (situation, thoughts, and behavior associated with momentary affective states).

Individual qualitative interview (Fraser \& Gondim, 2004; Warren, 2001): the objective was to explore the impressions, beliefs, opinions, and experiences of the participants. The interview script before and after the intervention with mindfulness was similar, thus making it possible to compare the two moments of data collection, addressing the following topics: (i) knowledge about mindfulness, in order to understand if there were changes in the conception of this construct based on the daily experience of the practices; (ii) expectations related to the intervention, to identify if there was a change in expectations based on the mindfulness experience and what were the students' intentions about continuing with the practices after the training; (iii) carrying out mindfulness practices, to explore the frequency and regularity in the practices during the intervention and afterwards; (iv) demands of graduate studies, aiming to relate them to the student's perception of stress and well-being; and (v) affective states towards graduate studies and life in general, with the objective of identifying which are the prevalent affective states and possible associations with the increase in mindfulness practices.

\section{Data Collection Procedure}

The study was approved by the Ethics Committee of the higher education institution where the research was carried out via Plataforma Brasil (CAEE: 71,455,317.2.0000.5686). All participants and the first author signed the Free and Informed Consent Form (ICF).

Participants were randomly allocated (draw, as specified in "Participants") to the four intervention condition subgroups and the control group. At moment 1, both the participants in the intervention subgroups, done concurrently, but on alternate days, and those in the control group, were submitted to individual interviews and filled out the instruments. Upon completing the 8 weeks of the intervention, totaling $16 \mathrm{~h}$, the participants were again interviewed and filled out the same instruments. During the 2-month period, the control group did not participate in any activity. Only after the second data collection moment, did the participants in the control group undergo the intervention.

All interventions were conducted by the researcher, a certified instructor. The individual interviews with each participant in the pre- and post-intervention 
moments were carried out in a private room, without noise or interference, by a trained interviewer, a member of the research group who had participated as an interviewer in the first stage, but who had not monitored the intervention. They were also recorded in audio, after the participant's consent.

During the 8-week intervention, each participant was asked twice a week to complete Cogni information on days and times not previously established. The point was to surprise the participant, avoiding planned responses. The instruction was to access the application and fill in the requested information about how they felt at the moment, the situation that was being experienced, current thoughts, and actions taken regarding the situation.

\section{Data Processing and Analysis Procedure}

Quantitative (self-report scales) and qualitative (individual interviews) data were compared, observing the intragroup (before and after the intervention within each group) and intergroup (control and intervention, considering the pre- and post-intervention moments) aspects.

The values for skewness, kurtosis, and the Shapiro-Wilk test of all variables used in the study in the pre- and post-intervention moments did not violate the assumptions of normality, authorizing the use of parametric tests. As there was no violation of the assumption of normal distribution of the residuals and recognizing that the participants were randomly allocated to the groups, repeated-measure analysis of variance (ANOVA) was used, with the analysis parameters being time (pre and post), group condition (intervention and control), and the overall scores of the scales for mindfulness, psychological well-being, and perceived stress.

The Cogni data was exported to an Excel spreadsheet for processing and analyzing the information. The frequency of response and mood of the participants in the intervention group were taken into account. The use of this application was intended to monitor the affective states of the participants during the mindfulness-based intervention program, as a complementary data item for interpreting the participant's perceived well-being.

Finally, the interviews were converted from audio to text by one of the researchers. The first two authors adopted the coding procedure and thematic category analysis of each of the interview topics in order to respond to the research problem. Words or excerpts from the participants' statements were coded, grouping them by similarities of meaning, and aligned with the concepts covered in the study (Bardin, 2010; Gondim \& Bendassolli, 2014). The thematic category structure was analyzed by another member of the research group who had not monitored the intervention nor conducted the interview.

\section{Results}

\section{Mindfulness, Perceived Stress, and Psychological Well-Being}

Table 1 and Fig. 1 show the increase for the Intervention Group (IG) in the FFMQ $\left[F(1.43)=24.25 ; p=0.00001 ; \eta_{p}^{2}=0.36\right]$, decrease in the PSS $[F(1.43)=18.84$; $\left.p=0.00008 ; \eta_{p}{ }^{2}=0.30\right]$, and increase in the PWBS $[F(1.43)=9.05 ; p=0.004$; 
Table 1 Means and standard deviations (in parentheses) of the assessments of mindfulness, perceived stress, and psychological well-being of the intervention and control groups in the pre- and post-intervention

\begin{tabular}{|c|c|c|c|c|c|c|}
\hline & \multicolumn{2}{|c|}{ Mindfulness } & \multicolumn{2}{|c|}{ Perceived stress } & \multicolumn{2}{|c|}{ Well-being } \\
\hline & Pre & Post & Pre & Post & Pre & Post \\
\hline Intervention & $\begin{array}{l}3.15 \\
(0.09)\end{array}$ & $\begin{array}{l}3.57 \\
(0.07)\end{array}$ & $\begin{array}{l}2.19 \\
(0.10)\end{array}$ & $\begin{array}{l}1.71 \\
(0.09)\end{array}$ & $\begin{array}{l}4.82 \\
(0.12)\end{array}$ & $\begin{array}{l}5.06 \\
(0.11)\end{array}$ \\
\hline Control & $\begin{array}{l}2.98 \\
(0.19)\end{array}$ & $\begin{array}{l}2.92 \\
(0.15)\end{array}$ & $\begin{array}{l}2.28 \\
(0.21)\end{array}$ & $\begin{array}{l}2.20 \\
(0.20)\end{array}$ & $\begin{array}{l}4.51 \\
(0.25)\end{array}$ & $\begin{array}{l}4.38 \\
(0.25)\end{array}$ \\
\hline
\end{tabular}

Mindfulness scale ranged from 1 to 5 , with 5 being the highest mindfulness index; perceived stress from 0 to 4 , with 4 indicating more perceived stress, and psychological well-being from 1 to 6 , where 6 indicates greater perceived well-being

$\left.\eta_{p}{ }^{2}=0.17\right]$ scores, in comparison with the control group (CG) [CG pre- and postresults for the FFMQ: $\left.F(1.43)=0.08 ; p=0.77 ; \eta_{p}{ }^{2}=0.00\right]$ [CG pre- and post-results for perceived stress: $\left.F(1.43)=0.091 ; p=0.76 ; \eta_{p}{ }^{2}=0.002\right]$ [CG pre- and post-results for psychological well-being: $\left.F(1.43)=0.51 ; p=0.48 ; \eta_{p}{ }^{2}=0.012\right]$.

\section{Analysis of Cogni}

In total, 16 messages were sent during the 2 months of intervention (two messages per week) on days and times drawn at random between 8 am and $9 \mathrm{pm}$ to all participants in the intervention group, with the aim of monitoring the most frequent affective states during the intervention. The response frequency throughout the intervention had a minimum of one response (one participant) and a maximum of 15 responses (six participants). The mood most mentioned in these responses was "happy," followed by "normal," while the mean was 3.7 (point between the "normal" and "happy" moods, closer to "happy"). In total, we had the following frequency of readings in the affective states: 244 happy, 156 normal, 50 very happy, $38 \mathrm{sad}$, and 12 very sad. Thus, a prevalence of positive affective state (happy) was observed among the participants during the intervention.

\section{Analysis of the Interviews}

In this section, we will discuss the interview data only for the participants who underwent the intervention, considering that the focus was to capture information about possible changes resulting from participation in the proposed intervention.

\section{Knowledge About Mindfulness}

After the intervention, the participants indicated that they had increased their understanding of the philosophical aspect of mindfulness practice, not

Fig. 1 Comparison of the overall scores for mindfulness (top), perceived stress (center), psychological well-being (bottom) in the pre- and post-intervention, intervention and control groups 

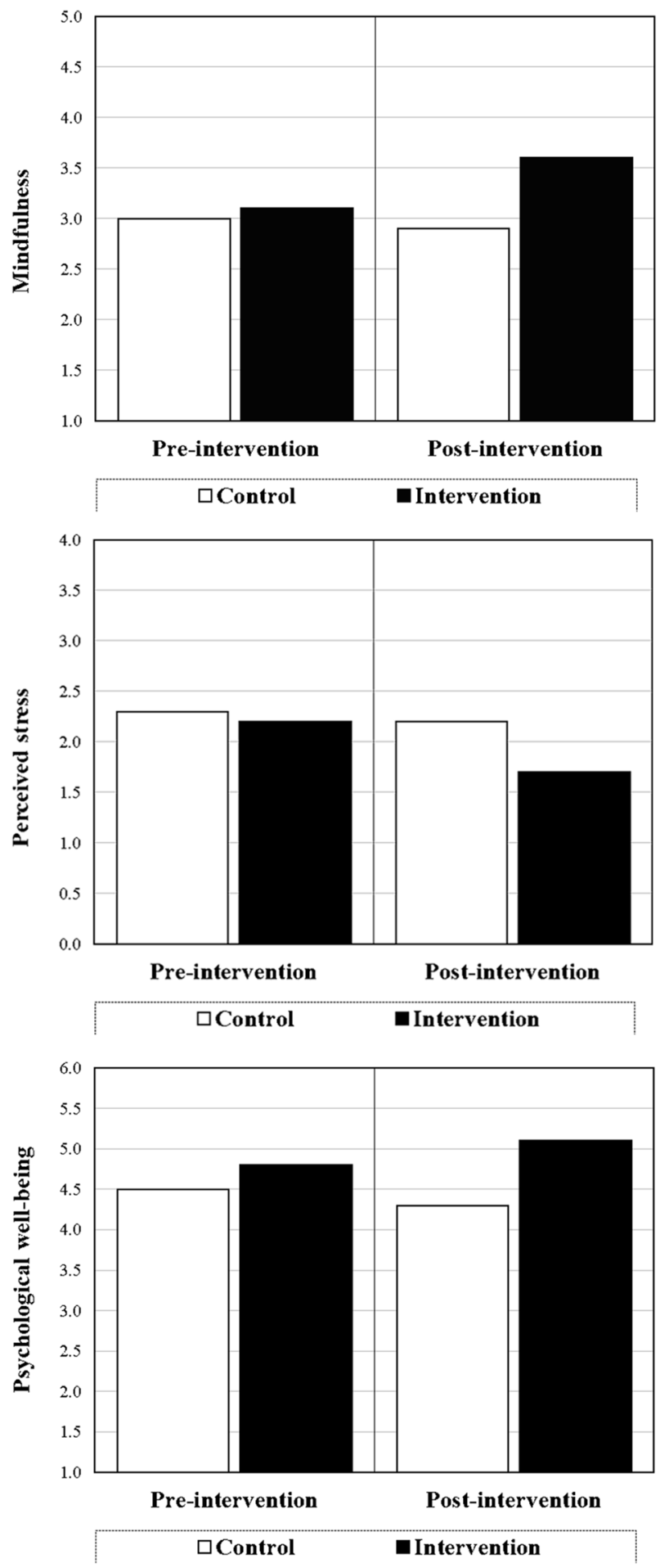
restricting it to a meditation technique, as was more evident in the initial preintervention interview. This new perspective helps in the transfer and generalization of the concepts learned for the daily lives of the individuals, as it brings more clarity about how mindfulness attitudes, for example, can be present in relationships and positions towards life. In addition, many participants emphasized in the second interview that the practice helped in the process of self-knowledge, since they were more attentive to body sensations, thoughts, breathing, and emotions. Even though, in the first interview, the expectations regarding mindfulness were focused on the cognitive and emotional aspects that this practice could help, giving more focus and allowing relaxation, the participants identified that there were gains in the development of greater awareness of themselves (Table 2).

\section{Expectations Related to the Mindfulness-Based Intervention}

The expectations about the intervention proved to be in line with the answers to the previous question, because in the post-intervention moment, the participants reported that they were realizing that the practice of mindfulness helped in the development of greater awareness (of themselves, body, breathing, contextual elements), but also of the potential of applying the technique and philosophical aspects, such as mindfulness attitudes, in their daily lives. This allowed the participants to see how much the practice of mindfulness helped them to develop new perspectives regarding the problems of graduate studies, such as handling time pressure, conflicts, and also changes in habits and postures. Thus, even though in the first interview the expectation of cognitive gains (improvement of focus, concentration, and organization of thinking) and emotional gains (experience of relaxation or reduction of stress) prevailed, after the training, the gains were related to the incorporation of the practice in daily life and the development of awareness (Table 3).

\section{Carrying Out Mindfulness Practices}

In the post-intervention interview, a question about the frequency of the practices (formal and informal) was added. Most participants $(n=29,78 \%)$ reported engaging in such practices on a daily basis, almost every day, or four times a week; six said they made little use of informal practices, sometimes, or two to three times a week. Only two participants reported not performing the practices. Regarding formal practices, thirteen participants (35\%) mentioned having a regular frequency, doing them daily, almost every day, or four times a week; thirteen said little, sometimes, or two or three times a week; and 11 were not performing formal practices. 


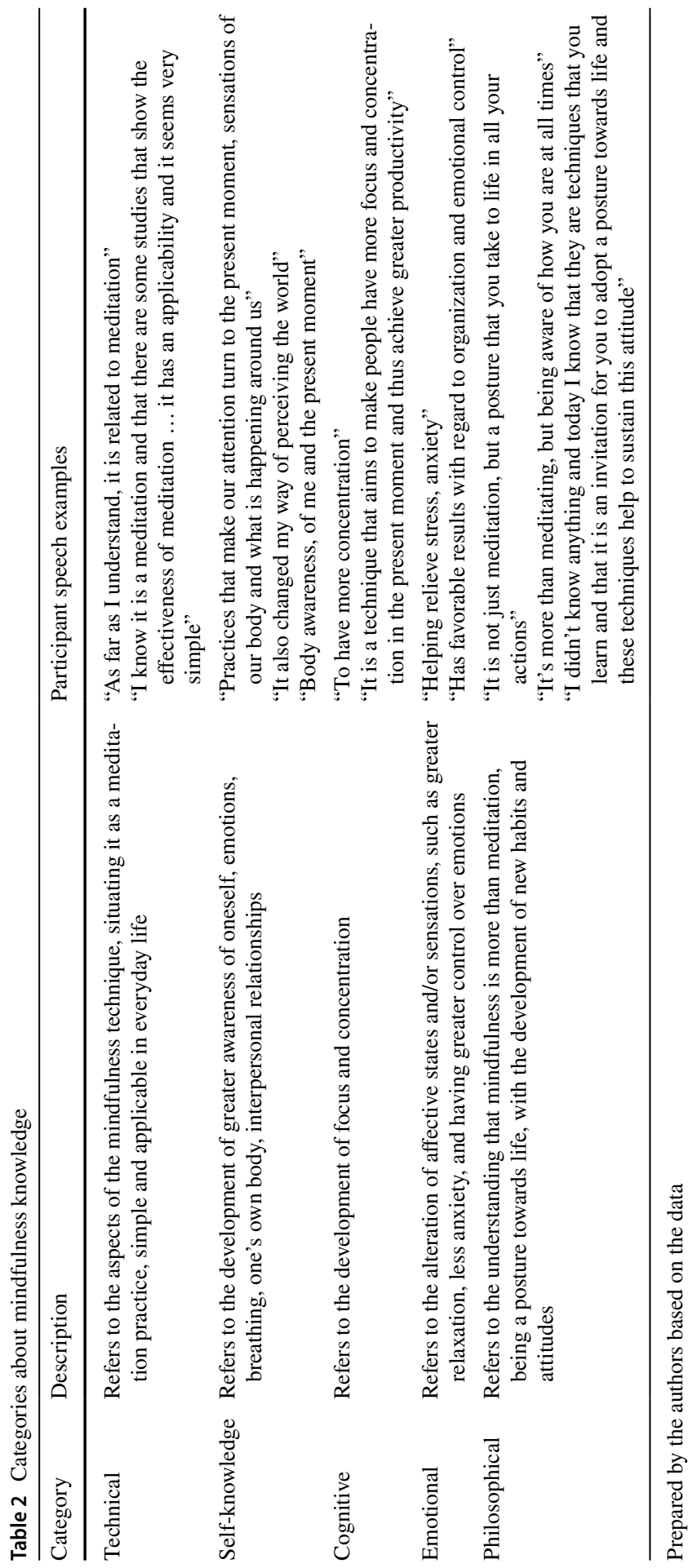




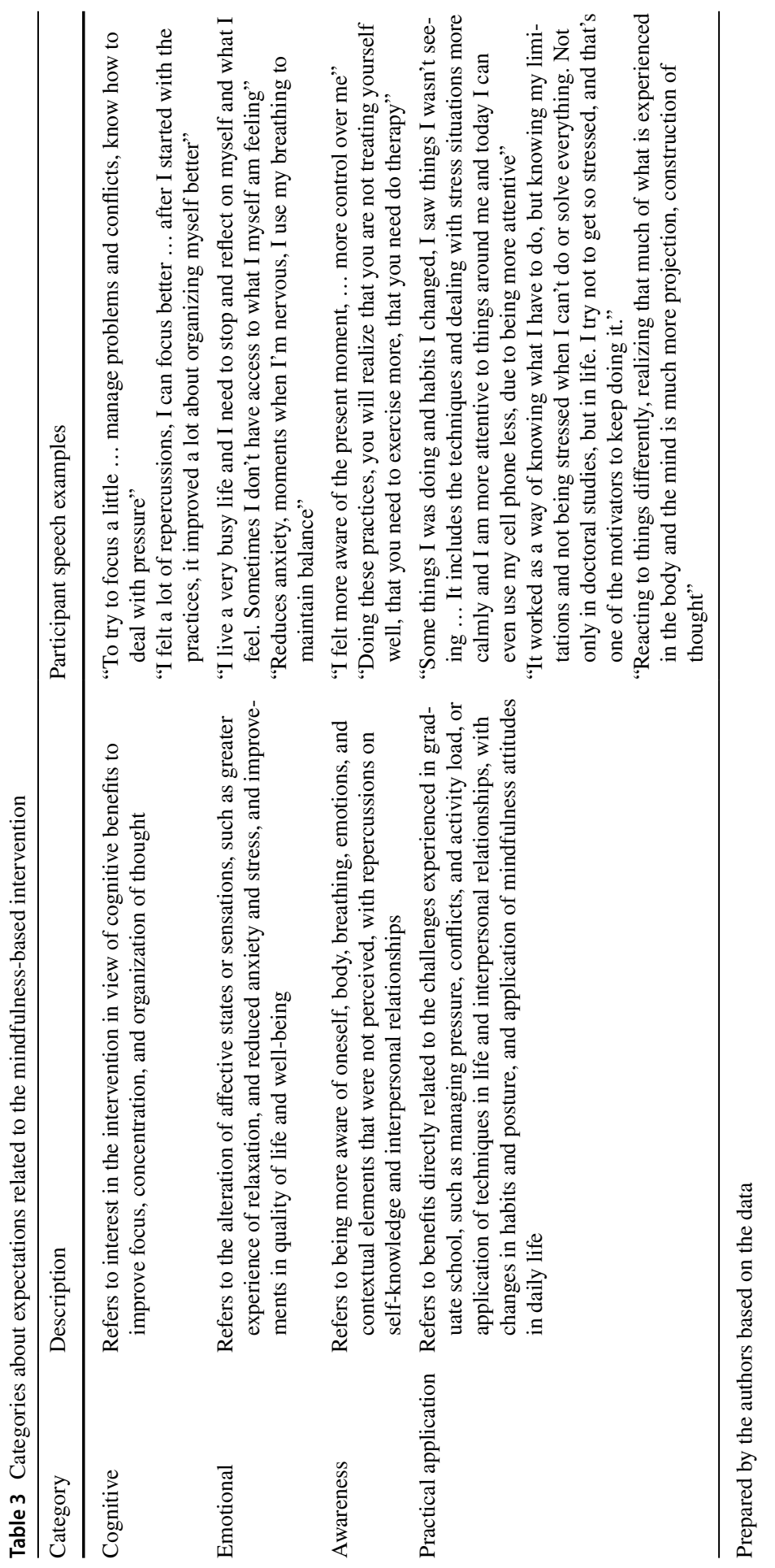




\section{Graduate School Demands}

The participants reported having managed to reframe some of the academic demands after the intervention, adopting new analysis perspectives and new attitudes and behaviors regarding the challenging situations, post-intervention. In addition to understanding and learning from their positive and negative experiences in graduate school, they managed to improve the planning and execution of activities, with greater focus and better management of time and deadlines. In the first interview, by contrast, the focus fell more on general issues inherent to the research process, such as the project's theme, career concerns, scientific production, and the structure of the university. They also made more comments about the impacts of their emotions (fear, insecurity) and personal situations (change of city, lack of family support, personal demands) in the graduate school experience. The results suggest that mindfulness may have helped them find alternative ways to deal with problems, including those of an interpersonal nature. Relational problems appeared more in the first interview than in the post-intervention interview (Table 4).

\section{Affective States Towards Graduate School and Life in General}

Regarding the affective states most present in life in general and in graduate school, there was a strong reference to ambivalent states, such as joy, satisfaction, and fulfillment, accompanied by anxiety, distress, and insecurity in the two interviews carried out. In the second interview, there was more mention of pleasant affective states and less of unpleasant affective states in comparison with the pre-intervention interview (Table 5).

\section{Discussion}

This study aimed to assess the effects of mindfulness practices (mindfulness as a technique) on mindfulness (mindfulness as a state of consciousness), perceived stress, and psychological well-being, in graduate students. The results indicated that initially, in both groups (control and intervention), the scores for mindfulness and perceived stress were very close to the midpoint of the scale, which indicates the equivalence of these groups resulting from the success of the participant randomization procedure. After the intervention, however, the control group maintained their levels of mindfulness, perceived stress, and well-being, while the intervention group presented an increase in mindfulness and well-being, and a reduction in perceived stress. The analysis of the interviews offered interpretative support for this result.

It must be considered, however, that these variations in the scores of the intervention group, although significant, presented a moderate effect size. One of the possible interpretations may be in the varied engagement in the tasks proposed by the instructor, considering that most of the participants in the intervention group engaged in informal practices, although a minority maintained regularity in the formal practices. It is important to highlight the complementarity of the formal and informal practices, since the formal assists in mindfulness quality, while the informal enables the daily experience (induction of a state) of mindfulness. 


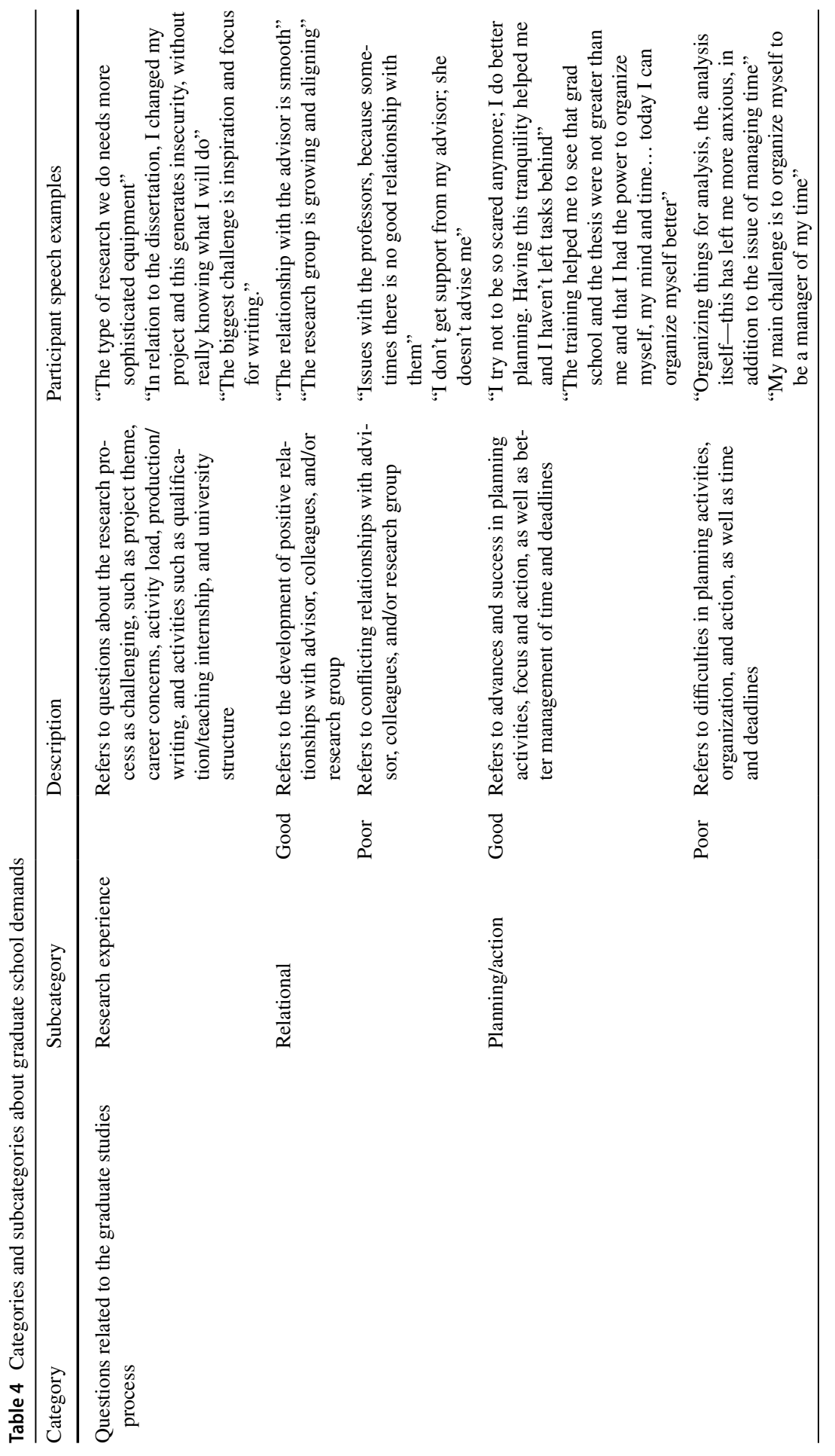




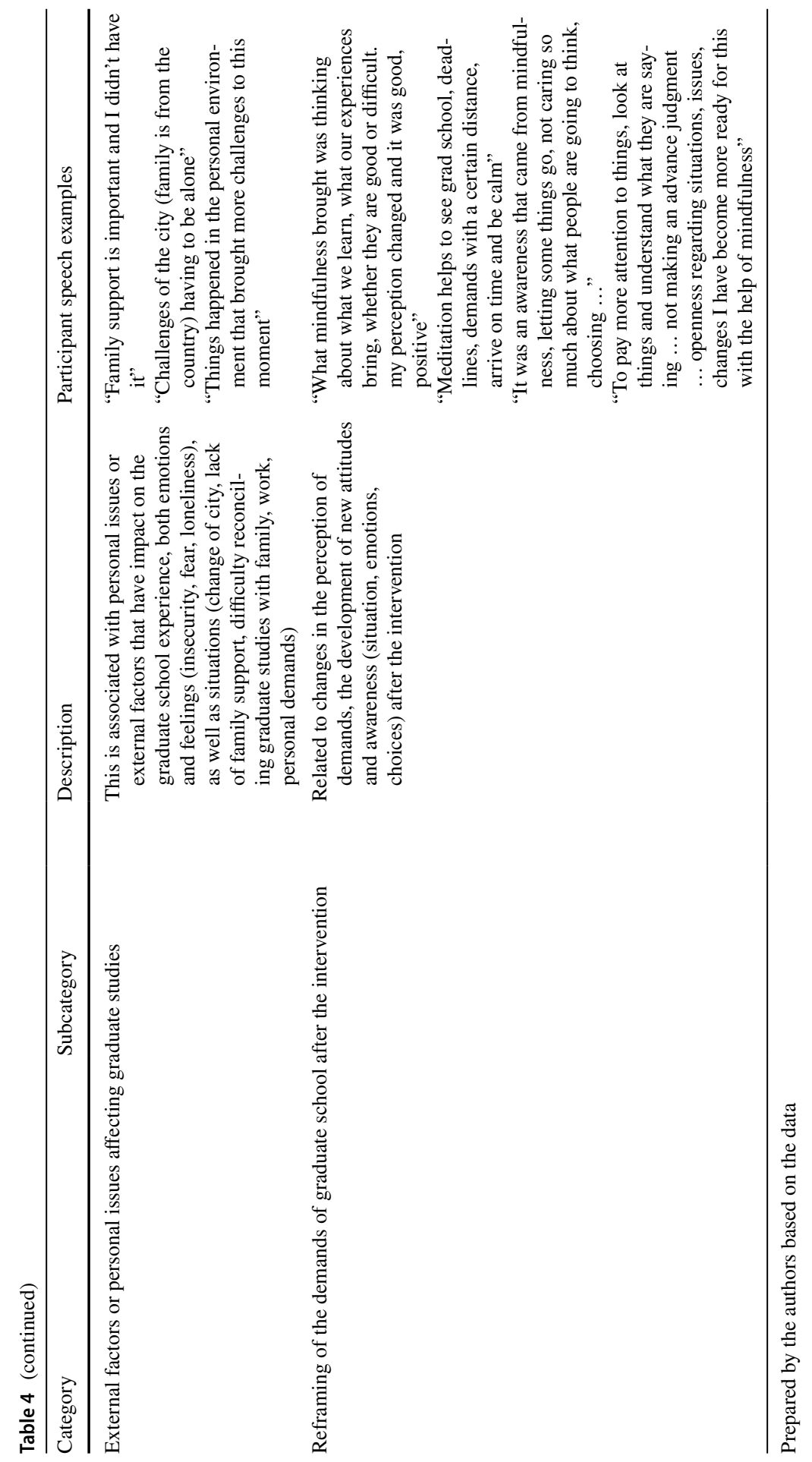




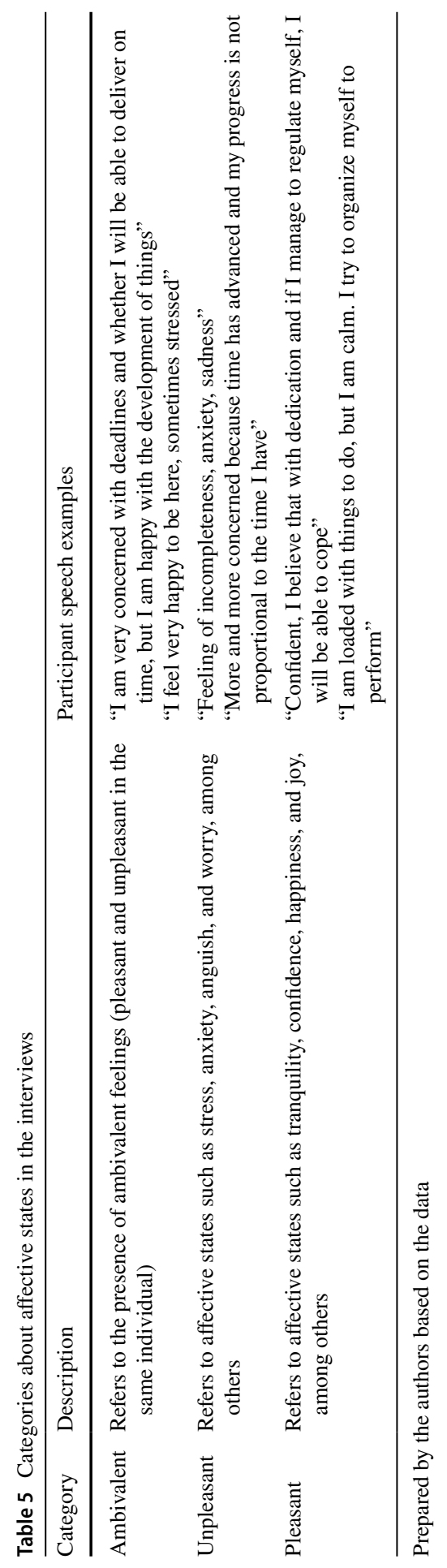


On the other hand, studies (Hindman et al., 2015) indicate that engaging in informal practices on a regular basis has impacts on reducing stress, just as formal practices do.

Thus, evidence in the literature also points out that the benefits of mindfulness depend on regular practice (Goldberg et al., 2014; Kabat-Zinn, 2017). A meta-analysis study conducted by Parsons et al. (2017) identified a small, but significant, association between formal home practice and the benefits of mindfulness intervention. On the other hand, Crane et al. (2014) found no evidence of an association between informal practices and the benefits of mindfulness-based intervention but reflected on the difficulty of measuring these practices, since they are less structured than formal ones.

The formal mindfulness technique that focuses on breathing, for example, does not propose a change in emotional or physical states but only observes them as they appear and accepts them as experiences, keeping the focus on the sensations of breathing. This posture can generate a change in the perception of the demands of the context, as reported by graduate students, with the visualization of aspects not previously perceived. The conscious sustaining of attention enables the development of a more flexible and adaptive emotion regulation, facilitated by the expansion of awareness and perception of the here and now (Alkoby et al., 2018; Roemer et al., 2015; Shapiro et al., 2006).

In this perspective, the data from the interviews provide support, since the reference to the increase in self-awareness (breathing, body, emotions, reactions) and changes in the perception of demands, development of new attitudes towards challenges, and greater awareness of the situations and choices stand out in the words of the participants, in the post-intervention moment. Greater awareness and capacity for observation help in choosing emotion regulation strategies that are more appropriate to the context, also offering feedback on the effectiveness of the strategies used (Coffey \& Hartman, 2008). This can give greater flexibility to the emotion regulation process, as the awareness of internal and external factors is increased and the freedom to choose the strategy to use makes the person become less reactive.

Although the indicators of well-being for both groups (control and intervention) were above the midpoint of the scale at the pre-intervention moment, the intervention group showed a small increase in the score. Evidence suggests that to maintain well-being, it is necessary to have a posture of acceptance in relation to one's emotions, a key aspect of the attitudes and the practice of mindfulness (Mitmansgruber et al., 2009).

In the interviews with the graduate students, it was also possible to capture some aspects related to the subjective experience of graduate school and the challenges inherent in this context. Although the perceived stress scores in the pre-intervention moment of both groups are close to the midpoint of the scale, the statements demonstrate ambivalent thoughts and feelings in relation to graduate school. The changes cited by the participants as a result of entering graduate school (routine, activity, and even city and social circle, in some cases) associated with the lack of institutional or relational support (difficulties in the relationship with advisor, research group, professors, and colleagues) and financial difficulties are potential stressors that are aggravated by the difficulty of planning, short deadlines, external and internal demands, and uncertainties regarding the future. Some students also reported the need to reconcile graduate education with other work activities, with difficulties related to time, fatigue, and prioritizing activities.

The literature points to numerous interrelated variables in the academic training process at the stricto sensu level that can generate feelings of anxiety and lack of control, with 
psychological distress (Faro, 2013b; Farrer et al., 2016; Mendes \& Iora, 2014). Some of these were also cited by the students in this study, such as running the research project, excess hours of study, poor academic performance evaluations, relationship with advisor, reconciling with one's personal life, demand for productivity, deadlines, and institutional problems (Galvan et al., 2015; Graner \& Cerqueira, 2019; Hoffmann et al., 2018; Santos et al., 2015).

In some post-intervention interviews, the students mentioned improvements in planning and execution, indicating better focus and achievement of graduate school tasks, and better management of time and deadlines. This data is in line with the result found by $\mathrm{Ju}$ and Lien (2016) in which the strategy of focusing attention on breathing (one of the practices of mindfulness) proved to be effective in reducing distracted minds and intrusive thoughts. This data can also be related to the reduction in perceived stress detected in the post-intervention in the intervention group.

The analysis of these data indicates that mindfulness training can be understood as a resource for coping with emotional situations (Shapiro et al., 2006) with a focus on the actual experience (Bishop et al., 2004), contributing to emotion regulation, reducing stress, and increasing well-being. The focus on the seven mindfulness attitudes (posture towards life) also proves relevant, since they are the fundamentals of the practice. According to Kabat-Zinn (2017), the attitude during the practices is decisive for the development of mindfulness. Each formal or informal practice and the changes of habit provide rich reflections about the seven mindfulness attitudes and, through the process of transference and generalization, such attitudes can come to be incorporated into the experiences of everyday life. It cannot be said for certain why, in this study, the informal practices were retained in the learning process more than the formal ones. Perhaps because they are easier to incorporate, since formal practices require the formation of habit, supported by systematic repetitions.

Finally, in relation to the procedural measures instrument (Cogni), it was observed that the predominant mood during the intervention was "happy" and "normal" and there is a possible connection with the data collected in the post-intervention interview, in which a slight decrease in negative affects and an increase in positive affects were identified, even though the predominant reference was to ambivalence (referring to the simultaneous presence of positive and negative affects). The increase in the overall psychological well-being score of the participants in the intervention group can be associated with the presence of more positive affects.

According to Erisman and Roemer (2010), there is empirical support for the relationship between mindfulness, positive affect, and well-being (Baer et al., 2006; Brockman et al., 2017; Brown \& Ryan, 2003), since the cultivation of an attitude centered on the present and without judgment in relation to emotional experiences can promote greater awareness and attention to positive events, adding richness and depth to these experiences and contributing to a feeling of greater well-being. In the present study, some attitudes, cultivated in the homework related to gratitude and awareness of emotions, for example, may have favored the emergence of positive affects and increased self-awareness. In the post-intervention interview, some participants commented that the practice of mindfulness made contextual aspects visible that previously went unnoticed.

The data also point to the ambivalence of affects of the graduate students, which may be related to the academic context. Although students long for an academic career and value it, they are not always emotionally prepared for the excessive demands, the pressure for productivity, the short deadlines, and the competitiveness. This ambivalent 
experience was also identified in the study by Bujdoso and Cohn (2008) in which, despite the stressful moments brought on by graduate school, the students also saw its positive aspects, as a critical space for reflection and legitimization of knowledge.

As for the limitations of this study, it is highlighted that the number of participants in the control group $(n=8)$ was much lower than that in the intervention group $(n=37)$. Furthermore, the control group was not submitted to any intervention concurrently with the intervention group, in a neutral manner. The control group only went through the intervention in mindfulness after the completion of the intervention groups. Another limitation refers to the lack of control over the participants' beliefs about the effectiveness of mindfulnessbased interventions and the lack of measurement of anxiety and depression levels in the pre-intervention moment. A final limitation to be mentioned is that the study did not contemplate the effect of retaining the learning in mindfulness over time. Without systematic practice, incorporated into the individual repertoire, the effects achieved can be diminished.

\section{Conclusions}

The results point to improvements in the indicators of mindfulness and in the assessment of psychological well-being, in addition to a reduction in the perception of stress. The interviews clearly showed an increase in awareness regarding emotions, the body, and contextual aspects. There were also gains in the acquisition of new attitudes regarding challenges and in the quality of interpersonal relationships, and in the planning and execution of activities linked to graduate studies, which may be associated with the decrease in perceived stress. In summary, the mindfulness-based intervention presented gains for psychological well-being, increased mindfulness (as a state), and reduced psychological stress for graduate students participating in this study.

Students experience ambivalent feelings in the graduate education process because, although they value academia, they experience much distress in this context. Mindfulnessbased interventions can help strengthen coping strategies to deal with this reality, preserving students' mental health and well-being. However, it is necessary to be clear about the limits of interventions at the individual level. More experienced coordinators, teachers, and advisors can offer support to these students who, although desiring to pursue an academic career, are emotionally unprepared to deal with so many demands. However, the sphere of action of graduate school programs is also limited, considering that the teachers and advisors are also subject to the same rules and institutional demands, with negative impacts on their well-being and health. This makes the need for structural changes evident, as well in the national graduate school system. In summary, the study contributes to fostering discussion about the need for actions aimed at preserving and promoting health and well-being in the academic environment, which in a worrying manner, has been provoking suffering.

\section{Appendix}

Table 6 


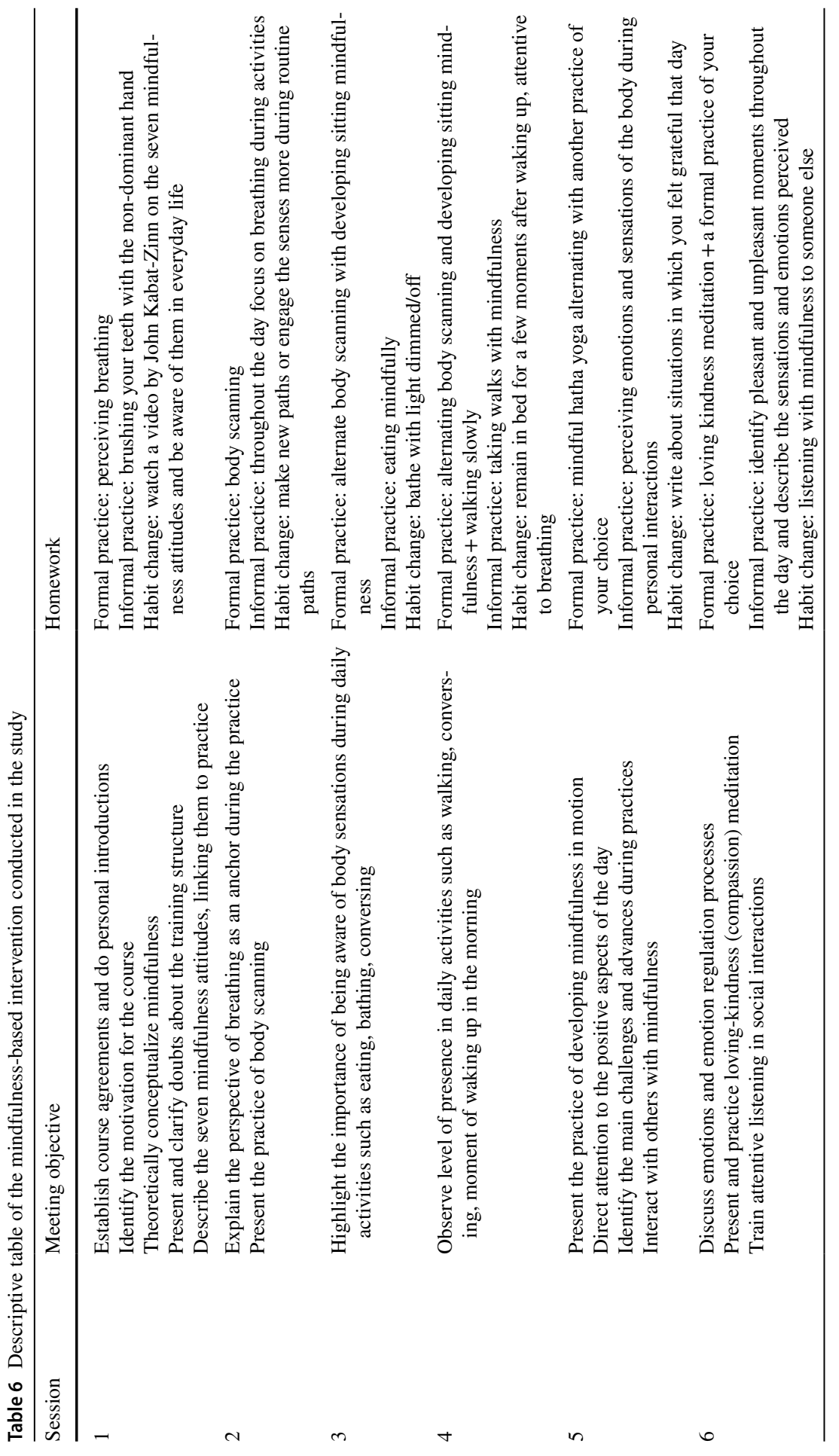




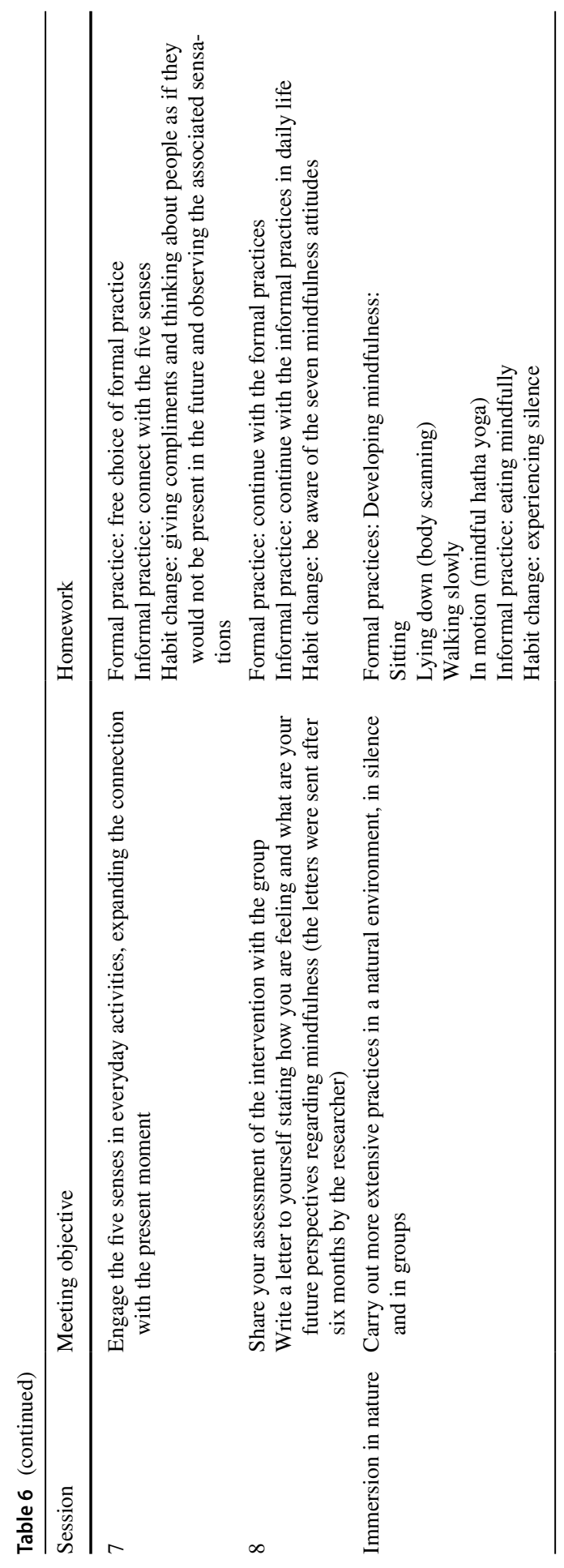


Supplementary Information The online version contains supplementary material available at https://doi. org/10.1007/s43076-021-00092-0.

\section{Declarations}

Ethics Approval and Consent to Participate All procedures performed in studies involving human participants were in accordance with the ethical standards of the institutional and/or national research committee (Comitê de Ética de Psicologia da Universidade Federal da Bahia-CAEE: 71455317.2.0000.5686) and with the 1964 Helsinki declaration and its later amendments or comparable ethical standards. Informed consent was obtained from all individual participants included in the study.

\section{References}

Alkoby, A., Pliskin, R., Halperin, E., \& Levit-Binnun, N. (2018). An eight-week mindfulness-based stress reduction (MBSR) workshop increases regulatory choice flexibility. Emotion, 19(4), 593-604. https://doi.org/10.1037/emo0000461

Baer, R. A., Smith, G. T., Hopkins, J., Krietemeyer, J., \& Toney, L. (2006). Using self-report assessment methods to explore facets of mindfulness. Assessment, 13(1), 27-45. https://doi.org/10.1177/10731 91105283504

Bardin, L. (2010). Análise de conteúdo. (4ª ed.). Edições 70.

de Barros, V. V., Kozasa, E. H., de Souza, I. C. W., \& Ronzani, T. M. (2014). Validity evidence of the Brazilian version of the five facet mindfulness questionnaire (FFMQ). Psicologia: Teoria e Pesquisa, 30(3), 317-327. https://doi.org/10.1590/S0102-37722014000300009

Beck, A. R., Verticchio, H., Seeman, S., Milliken, E., \& Schaab, H. (2017). A mindfulness practice for communication sciences and disorders undergraduate and speech-language pathology graduate students: Effects on stress, self-compassion, and perfectionism. American Journal of Speech-Language Pathology, 26(3), 893-907. https://doi.org/10.1044/2017_AJSLP-16-0172

Bishop, S. R., Lau, M., Shapiro, S., Carlson, L., Anderson, N. D., Carmody, J., Segal, Z. V., Abbey, S., Speca, M., Velting, D., \& Devins, G. (2004). Mindfulness: A proposed operational definition. Clinical Psychology: Science and Practice, 11(3), 230-241. https://doi.org/10.1093/clipsy.bph077

Brockman, R., Ciarrochi, J., Parker, P., \& Kashdan, T. (2017). Emotion regulation strategies in daily life: Mindfulness, cognitive reappraisal and emotion suppression. Cognitive Behaviour Therapy, 46(2), 91-113. https://doi.org/10.1080/16506073.2016.1218926

Brown, K. W., \& Ryan, R. M. (2003). The benefits of being present: Mindfulness and its role in psychological well-being. Journal of Personality and Social Psychology, 84(4), 822-848. https:// doi.org/10.1037/0022-3514.84.4.822

Bujdoso, Y. L. V., \& Cohn, A. (2008). Universidade como coping para lidar com o trabalho na assistência do mestrando enfermeiro. Revista De Saúde Pública, 42(2), 273-278. https://doi.org/ 10.1590/S0034-89102008000200012

Bullis, J. R., Bøe, H. J., Asnaani, A., \& Hofmann, S. G. (2014). The benefits of being mindful: Trait mindfulness predicts less stress reactivity to suppression. Journal of Behavior Therapy and Experimental Psychiatry, 45(1), 57-66. https://doi.org/10.1016/j.jbtep.2013.07.006

Coffey, K. A., \& Hartman, M. (2008). Mechanisms of action in the inverse relationship between mindfulness and psychological distress. Complementary Health Practice Review, 13(2), 79-91. https://doi.org/10.1177/1533210108316307

Cohen S, Karmack T, \& Mermelsteinm R. (1983). A global measure of perceived stress. J Health Soc Behav, 24(4):385-396. http://www.jstor.org/stable/2136404

Crane, C., Crane, R. S., Eames, C., Fennell, M. J. V., Silverton, S., Williams, J. M. G., \& Barnhofer, T. (2014). The effects of amount of home meditation practice in Mindfulness Based Cognitive Therapy on hazard of relapse to depression in the Staying Well after Depression Trial. Behaviour Research and Therapy, 63, 17-24. https://doi.org/10.1016/j.brat.2014.08.015

Diener, E. (1984). Subjective well-being. Psychological Bulletin, 95(3), 542-575. https://eddiener. com/articles/1126 
Diener, E., Oishi, S., \& Tay, L. (2018). Advances in subjective well-being research. Nature Human Behaviour, 2, 253-260. https://doi.org/10.1038/s41562-018-0307-6

Disabato, D. J., Goodman, F. R., Kashdan, T. B., Short, J. L., \& Jarden, A. (2016). Different types of well-being? A cross-cultural examination of hedonic and eudaimonic wellbeing. Psychological Assessment, 28(5), 471-482. https://doi.org/10.1037/pas0000209

Doll, A., Hölzel, B. K., Mulej Bratec, S., Boucard, C. C., Xie, X., Wohlschläger, A. M., \& Sorg, C. (2016). Mindful attention to breath regulates emotions via increased amygdala-prefrontal cortex connectivity. NeuroImage, 134, 305-313. https://doi.org/10.1016/j.neuroimage.2016.03.041

Erisman, S. M., \& Roemer, L. (2010). A preliminary investigation of the effects of experimentally induced mindfulness on emotional responding to film clips. Emotion, 10(1), 72-82. https://doi. org/10.1037/a0017162

Faro, A. (2013a). Um modelo explicativo para o bem-estar subjetivo: Estudo com mestrandos e doutorandos no Brasil. Psicologia: Reflexão e Crítica, 26(4), 654-662. https://doi.org/10.1590/ S0102-79722013000400005

Faro, A. (2013b). Estresse e estressores na pós-graduação: Estudo com mestrandos e doutorandos no Brasil. Psicologia: Teoria e Pesquisa, 29(1), 51-60. https://doi.org/10.1590/S0102-3772201300 0100007

Farrer, L. M., Gulliver, A., Bennett, K., Fassnacht, D. B., \& Griffiths, K. M. (2016). Demographic and psychosocial predictors of major depression and generalised anxiety disorder in Australian university students. BMC Psychiatry, 16, 241. https://doi.org/10.1186/s12888-016-0961-z

Ford, B. Q., Lam, P., John, O. P., \& Mauss, I. B. (2018). The psychological health benefits of accepting negative emotions and thoughts: Laboratory, diary, and longitudinal evidence. Journal of Personality and Social Psychology, 115(6), 1075-1092. https://doi.org/10.1037/pspp0000157

Fraser, M. T. D., \& Gondim, S. M. G. (2004). Da fala do outro ao texto negociado: Discussões sobre a entrevista na pesquisa qualitativa. Paidéia (ribeirão Preto), 14(28), 139-152. https://doi.org/10. 1590/S0103-863X2004000200004

Galante, J., Dufour, G., Vainre, M., Wagner, A., Stochl, J., Benton, A., Lathia, N., Howarth, E., \& Jones, P. B. (2017). A mindfulness-based intervention to increase resilience to stress in university students (the Mindful Student Study): A pragmatic randomised controlled trial. Lancet Public Health, 3(2), e72-e81. https://doi.org/10.1016/S2468-2667(17)30231-1

Galvan, T. C., Branco, G. M., \& Saurin, T. A. (2015). Avaliação de carga de trabalho em alunos de pós-graduação em engenharia de produção: Um estudo exploratório. Gestão \& Produção, 22(3), 678-690. https://doi.org/10.1590/0104-530X1498-14

Goldberg, S. B., Del Re, A. C., Hoyt, W. T., \& Davis, J. M. (2014). The secret ingredient in mindfulness interventions? A case for practice quality over quantity. Journal of Counseling Psychology, 61(3), 491-497. https://doi.org/10.1037/cou0000032

Gondim, S. M. G., \& Bendassolli, P. F. (2014). Uma crítica da utilização da análise de conteúdo qualitativa em psicologia. Psicologia Em Estudo, 19(2), 191-199. https://doi.org/10.1590/1413-73722 0530002

Gondim, S. M. G., \& Rentería-Perez, E. (2019). Da pesquisa-ação à ciência do desenho (design science): A validade da pesquisa prática/intervenção e a produção do conhecimento. In M. N. Carvalho Freitas \& T. Cury-Pollo (Orgs). Instituições, saúde e sociedade: contribuições da Psicologia. (pp. 37-59). EdUMEG.

Graham, M. M., Lindo, J., Bryan, V. D., \& Weaver, S. (2016). Factors associated with stress among second year student nurses during clinical training in Jamaica. Journal of Professional Nursing, 32(5), 383-391. https://doi.org/10.1016/j.profnurs.2016.01.004

Graner, K. M., \& de Cerqueira, A. T. A. R. (2019). Revisão integrativa: Sofrimento psíquico em estudantes universitários e fatores associados. Ciência \& Saúde Coletiva, 24(4), 1327-1346. https:// doi.org/10.1590/1413-81232018244.09692017

Gross, J. J. (2015). The extended process model of emotion regulation: Elaborations, applications, and future directions. Psychological Inquiry, 26, 130-137. https://doi.org/10.1080/1047840X.2015. 989751

Gross, J. J., \& John, O. P. (2003). Individual differences in two emotion regulation processes: Implications for affect, relationships, and well-being. Journal of Personality and Social Psychology, 85(2), 348-362. https://doi.org/10.1037/0022-3514.85.2.348

Hindman, R. K., Glass, C. R., Arnkoff, D. B., \& Maron, D. D. (2015). A comparison of formal and informal mindfulness programs for stress reduction in university students. Mindfulness, 6, 873-884. https://doi-org.ez10.periodicos.capes.gov.br/https://doi.org/10.1007/s12671-014-0331-1 
Hoffmann, C., Marchi, J., Comoretto, E., \& de Moura, G. L. (2018). Relações entre autoconceito profissional e produtivismo na pós-graduação. Psicologia \& Sociedade, 30, e167961. https://doi.org/10. 1590/1807-0310/2018v30167961

Iani, L., Lauriola, M., Chiesa, A., \& Cafaro, V. (2019). Associations between mindfulness and emotion regulation: The key role of describing and nonreactivity. Mindfulness, 10(2), 366-375. https://doi. org/10.1007/s12671-018-0981-5

Jovanović, V. (2015). A bifactor model of subjective well-being: A re-examination of the structure of subjective well-being. Personality and Individual Differences, 87, 45-49. https://doi.org/10.1016/j. paid.2015.07.026

Ju, Y.-J., \& Lien, Y.-W. (2016). Better control with less effort: The advantage of using focused-breathing strategy over focused-distraction strategy on thought suppression. Consciousness and Cognition, 40, 9-16. https://doi.org/10.1016/j.concog.2015.12.002

Kabat-Zinn J. (2017). Viver a catástrofe total: como utilizar a sabedoria do corpo e da mente para enfrentar o estresse, a dor e a doença. Palas Athena.

Klainin-Yobas, P., Ramirez, D., Fernandez, Z., Sarmiento, J., Thanoi, W., Ignacio, J., \& Lau, Y. (2016). Examining the predicting effect of mindfulness on psychological well-being among undergraduate students: A structural equation modelling approach. Personality and Individual Differences, 91, 63-68. https://doi.org/10.1016/j.paid.2015.11.034

Kral, T. R. A., Schuyler, B. S., Mumford, J. A., Rosenkranz, M. A., Lutz, A., \& Davidson, R. J. (2018). Impact of short- and long-term mindfulness meditation training on amygdala reactivity to emotional stimuli. NeuroImage, 181, 301-313. https://doi.org/10.1016/j.neuroimage.2018.07.013

Luft, C. D. B., de Sanches, S. O., Mazo, G. Z., \& Andrade, A. (2007). Versão brasileira da Escala de Estresse Percebido: Tradução e validação para idosos. Revista de Saúde Pública, 41(4), 606-615. https://doi.org/10.1590/S0034-89102007000400015

MacDonald, H. Z., \& Baxter, E. E. (2017). Mediators of the relationship between dispositional mindfulness and psychological well-being in female college students. Mindfulness, 8(2), 398-407. https:// doi.org/10.1007/s12671-016-0611-Z

Machado, W. L., Bandeira, D. R., \& Pawlowski, J. (2013). Validação da psychological well-being scale em uma amostra de estudantes universitários. Avaliação Psicológica, 12(2), 263-272. http://pepsic. bvsalud.org/scielo.php?script=sci_arttext\&pid=S1677-04712013000200017\&lng=pt\&tlng=pt

Mahmoudzadeh, S., Mohammadkhani, P., Dolatshahi, B., \& Moradi, S. (2015). Prediction of psychological well-being based on dispositional mindfulness and cognitive emotion regulation strategies in students. Practice in Clinical Psychology, 3(3), 195-202. http://jpcp.uswr.ac.ir/article-1-212-en. html

Mandal, S. P., Arya, Y. K., \& Pandey, R. (2017). Mindfulness, emotion regulation, and subjective wellbeing: Exploring the link. SIS Journal of Projective Psychology \& Mental Health, 24, 57-63.

Marais, G. A. B., Shankland, R., Haag, P., Fiault, R., \& Juniper, B. (2018). A survey and a positive psychology intervention on french phd student well-being. International Journal of Doctoral Studies, 13, 109-138. https://doi.org/10.28945/3948

Mendes, V. R., \& Iora, J. A. (2014). A opinião dos estudantes sobre as exigências da produção na pósgraduação. Revista Brasileira de Ciências do Esporte, 36(1), 171-187. https://doi.org/10.1590/ S0101-32892014000100012

Mitmansgruber, H., Beck, T. N., Höfer, S., \& Schüßler, G. (2009). When you don't like what you feel: Experiential avoidance, mindfulness and meta-emotion in emotion regulation. Personality and Individual Differences, 46(4), 448-453. https://doi.org/10.1016/j.paid.2008.11.013

Parsons, C. E., Crane, C., Parsons, L. J., Fjorback, L. O., \& Kuyken, W. (2017). Home practice in mindfulness-based cognitive therapy and mindfulness-based stress reduction: A systematic review and meta-analysis of participants' mindfulness practice and its association with outcomes. Behaviour Research and Therapy, 95, 29-41. https://doi.org/10.1016/j.brat.2017.05.004

Regehr, C., Glancy, D., \& Pitts, A. (2013). Interventions to reduce stress in university students: A review and meta-analysis. Journal of Affective Disorders, 148(1), 1-11. https://doi.org/10.1016/j.jad.2012. 11.026

Roemer, L., Williston, S. K., \& Rollins, L. G. (2015). Mindfulness and emotion regulation. Current Opinion in Psychology, 3, 52-57. https://doi.org/10.1016/j.copsyc.2015.02.006

Ryff, C. D. (1989). Happiness is everything, or is it? Explorations on the meaning of psychological wellbeing. Journal of Personality and Social Psychology, 57(6), 1069-1081. 0022-3514/89/SOO. 75.

Ryff, C. D., \& Essex, M. J. (1992). The interpretation of life experience and well-being: The sample case of relocation. Psychology and Aging, 7(4), 507-517. https://doi.org/10.1037/0882-7974.7.4.507 
Santana, V. S., \& Gondim, S. M. G. (2016). Regulação emocional, bem-estar psicológico e bem-estar subjetivo. Estudos De Psicologia, 21(1), 58-68. https://doi.org/10.5935/1678-4669.20160007

dos Santos, A. S., Perrone, C. M., \& Dias, A. C. G. (2015). Adaptação à pós-graduação stricto sensu: Uma revisão sistemática de literatura. Psico-USF, 20(1), 141-152. https://doi.org/10.1590/141382712015200113

Schmidt, M., \& Hansson, E. (2018). Doctoral students' well-being: A literature review. International Journal of Qualitative Studies on Health and Well-Being, 13, 1. https://doi.org/10.1080/17482631. 2018.1508171

Shapiro, S. L., Carlson, L. E., Astin, J. A., \& Freedman, B. (2006). Mechanisms of mindfulness. Journal of Clinical Psychology, 62(3), 373-386. https://doi.org/10.1002/jclp.20237

Simonelli-Muñoz, A. J., Balanza, S., Rivera-Caravaca, J. M., Vera-Catalán, T., Lorente, A. M., \& Gallego-Gómez, J. I. (2018). Reliability and validity of the student stress inventory-stress manifestations questionnaire and its association with personal and academic factors in university students. Nurse Education Today, 64, 156-160. https://doi.org/10.1016/j.nedt.2018.02.019

Smith, G. D., \& Yang, F. (2017). Stress, resilience and psychological well-being in Chinese undergraduate nursing students. Nurse Education Today, 49, 90-95. https://doi.org/10.1016/j.nedt.2016.10.004

Sonnentag, S. (2015). Dynamics of well-being. Annual Review of Organizational Psychology and Organizational Behavior, 2(1), 261-293. https://doi.org/10.1146/annurev-orgpsych-032414-111347

Warren, C. A. B. (2001). Qualitative interviewing. In J.F. Gubrium \& J.A. Holstein (Eds). Handbook of Interview Research, Context \& Method (pp.83-102). Sage Publications Inc.

Xiao, Q., Zhao, X., Bi, G., Wu, L., Zhang, H., Liu, R., Zhong, J., Wu, S., Zeng, Y., Cui, L., Chen, Y., Wu, K., \& Chen, Z. (2019). Alterations of regional homogeneity and functional connectivity following short-term mindfulness meditation in healthy volunteers. Frontiers in Human Neuroscience, 13, 1-12. https://doi.org/10.3389/fnhum.2019.00376

Zhang, W., Ouyang, Y., Tang, F., Chen, J., \& Li, H. (2019). Breath-focused mindfulness alters early and late components during emotion regulation. Brain and Cognition, 135, 103585. https://doi.org/10. 1016/j.bandc.2019.103585

Zhang, Z., \& Yuan, K.-H. (2018). Practical statistical power analysis using Webpower and R (Eds). Granger, IN: ISDSA Press. https://webpower.psychstat.org/wiki/models/index 